\title{
Cannabis Use Disorders in Primary Care: Screening and Treatment Suggestions
}

Authors:

Suzanne D. Turner $(1,2)$

Maya Nader $(1,2)$

\section{Lisa Graves (3)}

\section{Affiliations:}

1. Department of Family and Community Medicine, St. Michael's Hospital, Toronto, ON

2. Department of Family and Community Medicine, University of Toronto, Toronto, $\mathrm{ON}$

3. Department of Family and Community Medicine, Western Michigan University Homer Stryker MD School of Medicine, Kalamazoo, MI

\section{Correspondence author:}

Suzanne D. Turner

E-mail: TurnerSu@smh.ca

Key words: Cannabis, marijuana, cannabis use disorder, and addiction

\begin{abstract}
:
Objective: To review, through case-based learning, the screening for and treatment of cannabis use disorders in primary care. Harm reduction modalities as it pertains to cannabis use are also reviewed.
\end{abstract}

Methods: PubMed was searched for studies on cannabis use disorders with a specific focus on screening and treatment modalities. The literature cited was reviewed for those relevant studies identified through PubMed.

Results: Problematic cannabis use can be screened for with a single question. A positive screening question can lead to more intensive screening with a validated questionnaire. A high score on a validated questionnaire may lead to examination of the DSMV criteria. Withdrawal symptoms can be treated with synthetic cannabinoids. Maintenance may involve cannabinoids or other medications but the evidence is more mixed for this setting. Harm reduction techniques may be useful in those that are not interested in cutting down or in those that are willing to reduce but not stop cannabis consumption. Brief intervention may be effective in the primary care setting. There are patients who should not use cannabis.

Conclusion: Primary care providers should screen for cannabis use disorders with a single question in those patients presenting with problems that could be related to substance use. More in-depth screening is triggered by a positive response. Withdrawal management, maintenance therapy and harm reduction are all within the scope of primary care providers and should be explored with the patients. If these interventions are unsuccessful, the patient can be referred to an addiction medicine specialist. 
Medical Research Archives, Vol. 5, Issue 7, July 2017

Cannabis Use Disorders in Primary Care: Screening and Treatment Suggestions

\section{Sources of Information}

PubMed was searched for English language studies on cannabis use disorders with a specific focus on screening and treatment modalities. The literature cited was reviewed for those relevant studies identified through PubMed. Major addiction-related Internet sites were reviewed for cannabis-related research and definitions.

\section{Introduction: Cannabis}

\subsection{What is cannabis and how is it used?}

Cannabis is the most commonly used illegal substance worldwide. ${ }^{1,2}$ Marijuana, the most commonly used form of the Cannabis sativa plant, is the dried flower and leaf form of the plant. It is most commonly smoked in a "joint" but bongs, a type of water pipe, can be used to deliver a large bolus of the active component of marijuana. It can be used alone or combined with nicotine. ${ }^{3}$ Currently some groups suggest vaporization as a mechanism to reduce harm from the combustion of the plant material leading to carcinogen production. ${ }^{4}$ The psychoactive component of cannabis is tetrahydrocannabinol (THC) and has mild euphoric effects. Marijuana has the least THC of the most common plant preparations, typically reported as $0.5 \%-5 \%$ THC. Research indicates that there has been an increase in THC content in recreational sources over time. ${ }^{5}$ Commercial preparations of cannabis developed for medical marijuana markets can have THC contents upwards of $20 \%$ and especially appeal to youth and young adults who are seeking the psychoactive effects of THC. ${ }^{6,7,8}$

\section{Cannabis Use Disorders}

\subsection{Cannabis Intoxication}

Cannabis intoxication occurs within 30 minutes after smoking and lasts approximately 1-2 hours. The effects are a mild euphoria, relaxation and perceptual alterations specifically in time distortion and intensification of normal experiences. Patients also report increased sociability, appetite, talkativeness and laughter. ${ }^{9}$ One in ten occasional users who try cannabis will reportedly become dependent, but these rates may rise to one in two daily users. ${ }^{10}$ This rate is similar to cocaine but far lower than heroin. However, since many more people try cannabis, this as a result accounts for the higher prevalence of cannabis use disorders $(2.9 \%)$ compared to cocaine $(1.8 \%)$ and heroin $(0.7 \%){ }^{11}$

\subsection{Cannabis Withdrawal}

Cannabis withdrawal is physiologically similar to nicotine withdrawal and its symptoms including irritability, anger, depression, insomnia and anorexia. ${ }^{12,13}$ The onset of withdrawal is typically 24-48 hours after last use and peaks at 4-6 days. The total duration, as a result of the intense fat solubility of THC, is 1-3 weeks. ${ }^{14}$ Women may experience more severe symptoms, particularly with respect to mood-related symptoms than men. ${ }^{15}$ Natural history studies of cannabis-quit attempts show that withdrawal symptoms are present even with short (less than 7 days) quit attempts. ${ }^{16}$

\section{Diagnosis of Cannabis Use}

\section{Disorders}

\subsection{Screening}

Studies in screening for cannabis use disorders have looked at questionnaires as well as single questions. Asking if patients have used daily or nearly daily may predict a 
Medical Research Archives, Vol. 5, Issue 7, July 2017

Cannabis Use Disorders in Primary Care: Screening and Treatment Suggestions

cannabis use disorder. ${ }^{17}$ The Severity of Dependence Scale (SDS), Cannabis Use Disorders Identification Test (CUDIT), Cannabis Abuse Screening Test (CAST) and the Problematic Use of Marijuana (PUM) test are all short questionnaire-based tests that can be used to quantify malfunctioning associated with cannabis use. ${ }^{18}$ CUDIT and more recent changes to the original questionnaire such as the CUDIT-R, have excellent sensitivity and specificity but may be too long (i.e. with 20 questions required for the CUDIT-R) and time intensive for use as a general screening tool. Studies in alcohol-related disorders show that single question-screening tools in primary care practice ${ }^{19,20}$ may improve barriers such as time constraints as well as lack of familiarity with more complex screening modalities. ${ }^{21,22,23}$ In the absence of definitive evidence to support a specific screening modality we prefer to ask patients presenting for an annual review or those presenting with signs or symptoms of cannabis use disorders about cannabis use and frequency of said use (Figure 1). Given that those who use cannabis daily or near daily (i.e. every other day) have five times the risk of the general population of developing a cannabis use disorder, we find this is a time-efficient screening question in a busy primary care practice and is supported by other substance use guidelines. ${ }^{24}$ We suggest asking patients: "How many times in the last week did you use cannabis?" Those who used cannabis more than 3 times per week are at high risk of a cannabis use disorder and can be further evaluated with an indepth screening/diagnostic tool.

\section{Figure 1: Common problems associated with cannabis use include the following: ${ }^{25}$}

- Depression and anxiety

- Psychosis

- Recurrent respiratory tract infections

- Chronic cough

- Sleep disturbances

- Poor school or work performance

- Relationship difficulties

- Nausea and vomiting

\subsection{Cannabis Use Disorders: Definitions}

The American Society of Addiction Medicine defines addiction as "a primary, chronic disease of brain reward, motivation, memory and related circuitry." ${ }^{26}$ The Severity of Dependence Scale (SDS), Cannabis Use Disorders Identification Test
(CUDIT), Cannabis Abuse Screening Test (CAST) and the Problematic Use of Marijuana (PUM) test are all short questionnaire-based tests that can be used to quantify malfunctioning associated with cannabis use. ${ }^{27}$ CUDIT and more recent changes to the original questionnaire such as the CUDIT-R, have excellent sensitivity and specificity but may be too long (i.e. with 20 
Medical Research Archives, Vol. 5, Issue 7, July 2017

Cannabis Use Disorders in Primary Care: Screening and Treatment Suggestions

questions required for the CUDIT-R) and time intensive for use for general screening in a primary care practice. ${ }^{28}$ Further, there are no data directly comparing test performance amongst specific populations and therefore the ideal test to use in specific primary care populations is not known. ${ }^{29}$ To some degree, all of these screening tools utilize criteria based in the DSM to characterize the risk of addiction. In the primary care office, if a patient screens positive based on the single question, then the provider needs to screen for an addiction. This can be done with further questioning to elucidate tolerance, withdrawal and harms which can then be useful in providing harm reduction advice and brief intervention. If the provider is not comfortable with a more fluid approach, a structured approach using a validated screening tool, such as the CUDIT, can be used.

The referral for treatment can include a referral to an addiction medicine specialist who will then use the Diagnostic Statistical Manual (DSM) criteria to make a formal diagnosis of an addiction. The DSMV replaced the language of dependence and abuse with substance use disorders. With respect to cannabis use disorders (CUD), mild CUD is characterized by 2 of 11 criteria, moderate CUD by 3-5 criteria and severe CUDs by 6 or more criteria (Figure 2). When receiving a report back from addiction medicine, the severity of the patient's CUD should be characterized and will likely help to inform the intensity and types of treatments that will be suggested.

\section{Figure 2: Cannabis Use Disorder DSMV Criteria ${ }^{30}$}

Hazardous use

Social/interpersonal problems related to use

Neglected major roles to use

Withdrawal

Tolerance

Used larger amounts for longer than intended

Repeated attempts to quit or control use

Much time spent using

Physical/psychological problems related to use

Activities given up to use

Craving 
Medical Research Archives, Vol. 5, Issue 7, July 2017

Cannabis Use Disorders in Primary Care: Screening and Treatment Suggestions

\section{Treatment of Cannabis Use Disorders}

\subsection{Brief Intervention}

SBIRT is a technique for delivery of early intervention and treatment for patients with substance use disorders or at risk of developing them. It consists of Screening, a quick assessment of the severity of the disorder; Brief Intervention, using motivational interviewing techniques to affect behavioral change; and Referral to Treatment for those patients requiring access to specialty care. It is a validated method that can easily be used by family physicians in a busy office setting. ${ }^{31}$ Primary care interventions in cannabis-using populations by general practitioners are limited in the literature but there is a trend towards effectiveness. These kinds of interventions have been shown to be effective in the management of other substance use disorders.

\subsection{Reduction Strategies}

The time-line follow-back method is a calendar-based method that is used to help patients document and follow their substance use (a link to a commonly used form can be found here). ${ }^{32}$ While originally developed for alcohol use disorders, it has been validated for use in cannabis use populations. ${ }^{33,}{ }^{34} \mathrm{We}$ generally find that patients have a hard time quantifying cannabis use as they are typically buying large quantities and report variation in joint size. As a result, we recommend that patients use a kitchen scale to weigh their cannabis prior to rolling in a joint. As a result, the patient can accurately document the number of grams used. This is useful in terms of educating the patient further about their use, but also can be useful in terms of accurately quantifying future cannabis reduction. We generally find that patients can tolerate $10-20 \%$ reduction in daily cannabis amount on a weekly basis based on our experience of advising patients with opioid and alcohol use disorders. With this low level reduction, withdrawal symptoms are minimized and generally do not require pharmacological treatment. If the patient chooses to stop without a reduction phase or is experiencing withdrawal symptoms, we generally treat with the pharmacological recommendations below.

\subsection{Harm Reduction Strategies}

While a patient is actively moving towards reduction or if the patient is not yet motivated to make changes in terms of their use, we generally make recommendations for reducing the harms associated with cannabis use. Our strategy is based on the lower risk cannabis use guidelines proposed by Fischer, et al (Figure 3) ${ }^{35}$ The greatest harms are associated with daily or near-daily cannabis use. As a first strategy we suggest that patients try to have days that they don't use cannabis if they are daily users and eventually move to having more days when they abstain than days they use. In order to reduce respiratory harms patients should avoid smoking combined cannabis and tobacco, avoid deep inhalation and use vaporizers (which are commonly available by mail-order or in cannabis shops). Vaporizers are purported to be safer than smoking joints, blunts or using water pipes. Oral cannabis consumption avoids the combustion by-products that are harmful in smoke, but the variable absorption is unpredictable and therefore is not recommended. When patients obtain a new cannabis source, they should use a test-dose to effectively titrate the cannabis to lowest amount that provides the desired psychoactive effect. This allows the patient to help discern whether the cannabis has been adulterated with other illicit substances such as opioids or stimulants. In areas where opioids are found in the (illicit) cannabis 
Medical Research Archives, Vol. 5, Issue 7, July 2017

Cannabis Use Disorders in Primary Care: Screening and Treatment Suggestions

supply, patients should be counseled to use with a friend (i.e. to avoid using by themselves), to use a test dose and to have naloxone on hand, in case of overdose. Conservative estimates suggest at least 3-4 hours between consumption and motor vehicle driving but some experts recommend upwards of 12 hours. Patients should be counseled about the risks of driving given the cognitive impairments that occur even if the patient does not feel impaired.

\section{Figure 3: Harm Reduction Strategies for Cannabis Consumption}

- $\quad$ Reduce to use to every other day or twice weekly (or less)

- Avoid cannabis and tobacco together

- Avoid deep inhalation

- Use vaporizers

- Use lower THC content products

- Titrate cannabis use THC to lowest amount that gives desired psychoactive effect

- Avoid oral cannabis consumption due to varying absorption

- Use a test-dose of a new cannabis product to avoid possible psychoactive effects of illicit contaminants (i.e. opioids, stimulants, etc), use with a buddy and have naloxone on hand in areas with high contamination rates with opioids

- Avoid driving within at least 4 hours of cannabis use

Certain populations should be advised that the risks of cannabis outweigh any potential or real benefits of cannabis use (Figure 4). Adolescents are at greater risk of psychotic illness, dependence and long-term cognitive effects of cannabis. Those with a family history of psychosis are at high risk of developing a non-reversible psychotic illness as a result of cannabis use. A history of another substance use disorder is a contradiction to cannabis use as these patients are more likely to develop a cannabis use disorder or trigger a relapse/worsening substance use disorder. Respiratory or cardiac disease can worsen with cannabis use, particularly when cannabis is smoked. Those planning pregnancy or breast-feeding should not use cannabis given the emerging evidence showing small for gestational age neonates and possible neurocognitive effects of in utero cannabis exposure. Given the high fat solubility of $\mathrm{THC}$, it can concentrate in breast milk, and there are no known safe quantities of THC when breast-feeding. 
Medical Research Archives, Vol. 5, Issue 7, July 2017

Cannabis Use Disorders in Primary Care: Screening and Treatment Suggestions

Figure 4: Populations for whom cannabis consumption is not appropriate: ${ }^{36,37}$

- $\quad$ Are under the age of 25

- Have a personal history or strong family history of psychosis

- Have a current or past cannabis use disorder

- Have an active substance use disorder

- Have cardiovascular disease (angina, peripheral vascular disease, cerebrovascular disease, arrhythmias)

- Have respiratory disease

- Are pregnant, planning to become pregnant, or breastfeeding

\subsection{Treatment of Withdrawal}

The goal of withdrawal treatment is to mitigate the negative reinforcing effects of cannabis withdrawal. The best pharmacotherapeutic evidence is for dronabinol, a synthetic cannabinoid compound with pharmacological similarity to THC. ${ }^{38}$ It was originally developed, approved and marketed for HIV/AIDS-related anorexia as well as nausea and vomiting secondary to chemotherapy. A double-blind, placebo control study of withdrawal symptoms using dronabinol $10 \mathrm{mg}$ PO QID showed improved self reports of anxiety, chills, insomnia and anorexia. There was a decrease in cravings, a decrease in weight loss and improved psychomotor task performance reported. However, there was no improvement in irritability. ${ }^{39}$ A second study looked at low dose of $10 \mathrm{mg}$ TID vs. higher dose of $30 \mathrm{mg}$ TID. This study found that higher doses almost completely abolished most withdrawal symptoms although there were improvements at the lower doses. There were improved rates of retention in treatment for those using the medication versus placebo, but no improvement in abstinence rates in the twelve-week trial. ${ }^{40}$ High fixed doses of Sativex (nabiximols: Tetrana- binex ${ }^{\circledR}$ and Nabidiolex ${ }^{\circledR}$ ) improved withdrawal symptoms in a proof-of-concept study and provided further evidence for reduced withdrawal symptoms with THClike compounds. ${ }^{41}$

Other pharmacological treatments for withdrawal have been studied with limited benefits. Mirtazapine with cognitive behavioral therapy (CBT) was studied in treatment seeking users and while there was a favorable impact on mood, there were no differences in sleep changes and other withdrawal symptoms. ${ }^{42}$ Zolpidem was found to normalize sleep efficiency and improved self-reports of sleep quality, but had no effect on sleep latency abnormalities common in cannabis withdrawal. 43 Nitrazepam improved several objective sleep-related abnormalities but was not effective in improving subjective sleep symptoms. This may indicate that sedatives and/or hypnotics are an effective class to help with sleep-related abnormalities associated with cannabis withdrawal, but further research is required and likely this class of medication should be limited to the withdrawal period (i.e. 12 weeks) given the risk of secondary dependency. Lithium carbonate was not helpful in managing sleep 
Medical Research Archives, Vol. 5, Issue 7, July 2017

Cannabis Use Disorders in Primary Care: Screening and Treatment Suggestions

disturbances. $^{44}$ Gabapentin at $1200 \mathrm{mg}$ per day improved withdrawal symptoms in a small study of adults and improved cognitive functioning. ${ }^{45}$ In adolescents, emerging evidence seems to point to a role of $\mathrm{N}$ acetyl-cysteine (NAC) in establishing abstinence. ${ }^{46}$ More research is required to look at its role in maintaining abstinence. There are mixed findings with respect to SSRIs and reduced cannabis consumption. ${ }^{47}$ If severe mood-related symptoms remain after detoxification, a trial of SSRI may be warranted if the practitioner suspects a cooccurring diagnosis. ${ }^{48}$

In our practice, dronabinol is not available as a result of a country-specific manufacturer issue and as a result we use nabilone, a synthetic THC analogue, titrated to withdrawal symptoms to a maximum dose of $2 \mathrm{mg}$ TID. In our practice, patients report a decrease in withdrawal symptoms and subjective measures of substance use.

\subsection{Maintenance Phase Treatment}

Multiple studies have shown that in terms of maintaining reduced consumption or abstinence, dronabinol will reduce withdrawal symptoms, but does not impact subjective effects of smoked cannabis and as a result, this may explain why it is not effective in helping maintain abstinence. ${ }^{49}$ In terms of maintaining abstinence, dronabinol improves withdrawal symptoms and treatment retention, but it does not increase abstinence rates over placebo and did not show any significant decrease in longer term consumption. ${ }^{50,51}$ Buspirone administered at $60 \mathrm{mg}$ a day did not improve self-reports of days of abstinence compared to placebo, but did show a trend towards negative urine drug screens in a 12-week study and a trend towards an earlier first negative urine when used in combination with motivational interviewing. ${ }^{52}$ A combined trial using dronabinol and lofexadine (alpha 2 agonist) showed these two medications were not effective in maintaining abstinence amongst cannabis dependent individuals. ${ }^{53}$ Atomoxetine has also been ineffective. A Cochrane review on therapies for cannabis dependence states that gabapentin, NAC and THC-based preparations are worthy of further research but the overall evidence is weak. ${ }^{54}$

\section{Conclusion}

Cannabis is the most commonly used illicit drug in North America. Cannabis use should be screened for amongst those that present to primary care with conditions that may be impacted by the use of this drug. A single screening question may be effective in identifying those that have problematic use and require further screening with a more involved tool such as the CUDIT. Brief interventions, by primary care providers, may be effective in reducing cannabis consumption. In the absence of trained addiction medicine specialists for referral, primary care providers can provide withdrawal pharmacotherapy with synthetic cannabinoids. Maintenance therapy with cannabinoids is not generally warranted but the primary care provider can continue to monitor the patient and provide support. Lower risk cannabis use should be reviewed with those patients that continue to use cannabis. 
Medical Research Archives, Vol. 5, Issue 7, July 2017

Cannabis Use Disorders in Primary Care: Screening and Treatment Suggestions

\section{Literature Cited:}

${ }^{1}$ Substance Abuse and Mental Health Services Administration. Results from the 2015 National Survey on Drug Use and Health: Detailed Tables, SAMHSA, CBHSQ [cited 2017 Apr 28]. Available from: http://www.samhsa.gov/data/sites/default/files/NSDUH-DetTabs-2015/NSDUHDetTabs-2015/NSDUH-DetTabs-2015.htm. Accessed October 11, 2016.

${ }^{2}$ Substance Abuse and Mental Health Services Administration. Substance Use Disorders. [cited 2017 Apr 28]. http://www.ccsa.ca/Eng/topics/Marijuana/Pages/default.aspx. Accessed April 1, 2017.

${ }^{3}$ Copeland J. Cannabis use and its associated disorders: clinical care. Australian Family Physician. 2016 Dec. 45 (12): 874-877.

${ }^{4}$ Gieringer, DH. Cannabis "Vaporization”. Journal Of Cannabis Therapeutics 2001; 1(3): 153170.

${ }^{5}$ Cascini F, Aiello C, Di Tanna G. Increasing delta-9-tetrahydrocannabinol ( $\left.\Delta-9-T H C\right)$ content in herbal cannabis over time: systematic review and meta-analysis. Curr Drug Abuse Rev. 2012 Mar;5(1): 32-40.

${ }^{6}$ American Chemical Society. Legalizing marijuana and the new science of weed. 2015 Mar 23 [cited Apr 30, 2017]. Available from: https://www.acs.org/content/acs/en/pressroom/ newsreleases/2015/march/legalizing-marijuana-and-the-new-science-of-weed-video.html.

${ }^{7}$ Popova L, McDonald EA, Sidhu S, Barry R, Richers Maruyama TA, Sheon NM, Ling PM. Perceived harms and benefits of tobacco, marijuana, and electronic vaporizers among young adults in Colorado: Implications for health education and research. Addiction. 2017 Apr 27. doi: 10.1111/add.13854. [Epub ahead of print]

${ }^{8}$ Freeman TP, Winstock AR.Examining the profile of high-potency cannabis and its association with severity of cannabis dependence. Psychol Med. 2015 Nov;45(15):3181-9.

${ }^{9}$ Budney AJ, Roffman R, Stephens RS, Walker D. Marijuana dependence and its treatment. Addict Sci Clin Pract. 2007 Dec; 4(1): 4-16.

${ }^{10}$ Hall W, Pacula RL. Cannabis Use and Dependence. Cambridge: Cambridge University Press; 2003.

11 Hasin DS, Tulshi DS, Kerridge BT, Goldstein RB, Chou SP, Zhang H. Prevalence of marijuana use disorders in the United States between 2001-2002 and 2012-2013. JAMA Psychiatry. 2015;72(12):1235-1242.

12 Budney AJ, Hughes JR. The cannabis withdrawal syndrome. Curr Opin Psychiatry. 2006 May;19(3):233-8. 
Medical Research Archives, Vol. 5, Issue 7, July 2017

Cannabis Use Disorders in Primary Care: Screening and Treatment Suggestions

${ }^{13}$ Allsop DJ, Bartlett DJ, Johnston J, Helliwell D, Winstock A, McGregor IS, Lintzeris N. The effects of lithium carbonate supplemented with nitrazepam on sleep disturbance during cannabis abstinence. J Clin Sleep Med 2015;11(10):1153 -1162 .

${ }^{14}$ Budney AJ, Roffman R, Stephens RS, Walker D. Marijuana dependence and its treatment. Addict Sci Clin Pract. 2007 Dec; 4(1): 4-16.

${ }^{15}$ Hermann ES, Weerts EM, Vandrey R. Sex differences in cannabis withdrawal in treatmentseeking cannabis users. Exp Clin Psychopharmacol. 2015 December ; 23(6): 415-421.

${ }^{16}$ Hughes JR, Naud S, Budney AJ, FIngar JR, Callas PW. Attempts to Stop or Reduce Daily Cannabis Use: An Intensive Natural History Study. Psychol Addict Behav 2016 May; 30(3): 389397.

${ }^{17}$ Blankers M, Frijns T, Belackova V, Rossi C, Svensson B, et al. (2014) Predicting Cannabis Abuse Screening Test (CAST) Scores: A Recursive Partitioning Analysis Using Survey Data from Czech Republic, Italy, the Netherlands and Sweden. PLoS ONE 9(9): e108298.

${ }^{18}$ Piontek D, Kraus L, Klempova D. Short scales to assess cannabis-related problems: a review of psychometric properties. Substance Abuse Treatment, Prevention, and Policy 2008, 3:25.

${ }^{19}$ Adamson SJ, Sellman JD. A prototype screening instrument for cannabis use disorder: the Cannabis Use Disorders Identification Test (CUDIT) in an alcohol-dependent clinical sample. Drug and Alcohol Review 2003, 22, 309 - 315.

${ }^{20}$ Adamson SJ, Kay-Lambdin FJ, Baker AL, Lewin TJ, Thornton L, Kelly BJ, Sellman JD. An improved brief measure of cannabis misuse: The Cannabis Use Disorders Identification TestRevised (CUDIT-R). Drug and Alcohol Dependence 2010; 110: 137-143.

${ }^{21}$ Williams R, Vinson DC. Validation of a single screening question for problem drinking. Journal of Family Practice 2001; 307.

${ }^{22}$ Seale JP, Boltri JM, Shellenberger S, Velasquez MM, Cornelius M, Guyinn M, Okosun I, Sumner H. Primary Care Validation of a Single Screening Question for Drinkers. Journal of Studies on Alcohol. 2006; 67(5), 778-784.

${ }^{23}$ Taj N, Devera-Sales A, Vinson DC. Screening for problem drinking: does a single question work? J Fam Pract. 1998 Apr;46(4):328-35.

${ }^{24}$ Blankers M, Frijns T, Belackova V, Rossi C, Svensson B, et al. (2014) Predicting Cannabis Abuse Screening Test (CAST) Scores: A Recursive Partitioning Analysis Using Survey Data from Czech Republic, Italy, the Netherlands and Sweden. PLoS ONE 9(9): e108298.

${ }^{25}$ Turner SD, Spithoff S, Kahan M. Approach to cannabis use disorder in primary care: focus on youth and other high-risk users. Can Fam Physician. 2014 Sep;60(9):801-8. 
Medical Research Archives, Vol. 5, Issue 7, July 2017

Cannabis Use Disorders in Primary Care: Screening and Treatment Suggestions

26 American Society of Addiction Medicine. Definition of Addiction [cited 2017 Apr 28]. Available from: http://www.asam.org/quality-practice/definition-of-addiction.

27 Piontek D1, Kraus L, Klempova D. Short scales to assess cannabis-related problems: a review of psychometric properties. Subst Abuse Treat Prev Policy. 2008 Dec 2;3:25. doi: 10.1186/1747-597X-3-25.

${ }^{28}$ Adamson SJ, Kay-Lambkin FJ, Baker AL, Lewin TJ, Thornton L, Kelly BJ, Sellman JD. An improved brief measure of cannabis misuse: the Cannabis Use Disorders Identification TestRevised (CUDIT-R). Drug Alcohol Depend. 2010 Jul 1;110(1-2):137-43.

29 Piontek D1, Kraus L, Klempova D. Short scales to assess cannabis-related problems: a review of psychometric properties. Subst Abuse Treat Prev Policy. 2008 Dec 2;3:25. doi: 10.1186/1747-597X-3-25.

30 Hasin DS ${ }^{1}$, O'Brien CP, Auriacombe M, Borges G, Bucholz K, Budney A, Compton WM, Crowley T, Ling W, Petry NM, Schuckit M, Grant BF. DSM-5 criteria for substance use disorders: recommendations and rationale.Am J Psychiatry. 2013 Aug 1; 170(8): 834-851.

${ }^{31}$ Substance Abuse and Mental Health Services Administration. Screening, brief intervention and referral to treatment (SBIRT) [cited 2017 Apr 30]. Available from: https://www.samhsa.gov/sbirt.

${ }^{32}$ National Institute on Drug Abuse. Time-line Follow-back Sample Form. Available from: https://cde.drugabuse.gov/sites/nida_cde/files/TimeLineFollowBack_2014Mar24.pdf

33 Robinson SM, Sobell LC, Sobell MB, Leo GI. Reliability of the Timeline Followback for cocaine, cannabis, and cigarette use. Psychol Addict Behav. 2014 Mar;28(1):154-62.

${ }^{34}$ Hjorthøj CR ${ }^{1}$, Hjorthøj AR, Nordentoft M. Validity of Timeline Follow-Back for self-reported use of cannabis and other illicit substances--systematic review and meta-analysis. Addict Behav. 2012 Mar;37(3):225-33.

35 Fischer B, Jeffries V, Hall W, Room R, Goldner E, Rehm J. Lower Risk Cannabis use Guidelines for Canada (LRCUG): a narrative review of evidence and recommendations. Can J Public Health. 2011 Sep-Oct;102(5):324-7.

${ }^{36}$ College of Family Physicians of Canada. Authorizing Dried Cannabis for Chronic Pain or Anxiety: Preliminary Guidance from the College of Family Physicians of Canada. Mississauga, On: College of Family Physicians of Canada; 2014

${ }^{37}$ Centre for Addiction and Mental Health. Cannabis Policy Framework [cited 2017 Apr 28]. Available from: https://www.camh.ca/en/hospital/about_camh/influencing_public_policy/ documents/camhcannabispolicyframework.pdf

${ }^{38}$ Marshall K, Gowing L, Ali R, Le Foll B. Pharmacotherapies for cannabis dependence. Cochrane Database Syst Rev. 2014 December 17; 12: CD008940. 
Medical Research Archives, Vol. 5, Issue 7, July 2017

Cannabis Use Disorders in Primary Care: Screening and Treatment Suggestions

${ }^{39}$ Haney M, Hart CL, Vosburg SK, Nasser J, Bennett A, Zubaran C, Foltin RW. Marijuana withdrawal in humans: effects of oral THC or divalproex. Neuropsychopharmacology. 2004 Jan;29(1):158-70.

${ }^{40}$ Budney AJ, Roffman R, Stephens RS, Walker D. Marijuana dependence and its treatment. Addict Sci Clin Pract. 2007 Dec; 4(1): 4-16.

${ }^{41}$ Trigo JM, Lagzdins D, Rehm J, Selby P, Gamaleddin I, Fischer B, Barnes AJ, Huestis MA, Le Foll B.Effects of fixed or self-titrated dosages of Sativex on cannabis withdrawal and cravings. Drug Alcohol Depend. 2016 Apr 1;161:298-306.

${ }^{42}$ Frewen AR, Baillie AJ, Montebello ME. Are cannabis users who participate in a randomized clinical trial different from other treatment seekers? J Subst Abuse Treat. 2009 Apr;36(3):33944.

${ }^{43}$ Vandrey R, Smith MT, McCann UD, Budney AJ, Curran EM. Sleep disturbance and the effects of extended-release zolpidem during cannabis withdrawal. Drug Alcohol Depend. 2011 Aug 1;117(1):38-44.

${ }^{44}$ Allsop DJ, Bartlett DJ, Johnston J, Helliwell D, Winstock A, McGregor IS, Lintzeris N. The effects of lithium carbonate supplemented with nitrazepam on sleep disturbance during cannabis abstinence. J Clin Sleep Med 2015;11(10):1153 -1162 .

${ }^{45}$ Mason, B.J., et al., A proof-of-concept randomized controlled study of gabapentin: effects on cannabis use, withdrawal and executive function deficits in cannabis-dependent adults. Neuropsychopharmacology, 2012. 37(7): p. 1689-98.

${ }^{46}$ Gray KM, Carpenter MJ, Baker NL, DeSantis SM, Kryway E, Hartwell KJ, McRae-Clark AL, Brady KT. A double-blind randomized controlled trial of N-acetylcysteine in cannabis-dependent adolescents. Am J Psychiatry. 2012 Aug;169(8):805-12.

${ }^{47}$ Marshall K, Gowing L, Ali R, Le Foll B. Pharmacotherapies for cannabis dependence. Cochrane Database Syst Rev. 2014 December 17; 12: CD008940.

${ }^{48}$ Quello, SB, Brady, KT, Sonne, SC. Mood Disorders and Substance Use Disorder: A Complex Comorbidity. Sci Pract Perspect. 2005 Dec; 3(1): 13-21.

${ }^{49}$ Hart $\mathrm{CL}^{1}$, Ward AS, Haney M, Comer SD, Foltin RW, Fischman MW.

Comparison of smoked marijuana and oral Delta(9)-tetrahydrocannabinol in humans. Psychopharmacology (Berl). 2002 Dec;164(4):407-15.

${ }^{50}$ Hart $\mathrm{CL}^{1}$, Haney M, Ward AS, Fischman MW, Foltin RW. Effects of oral THC maintenance on smoked marijuana self-administration. Drug Alcohol Depend. 2002 Aug 1;67(3):301-9. 
Medical Research Archives, Vol. 5, Issue 7, July 2017

Cannabis Use Disorders in Primary Care: Screening and Treatment Suggestions

${ }^{51}$ Levin FR, Mariani JJ, Brooks DJ, Pavlicova M, Cheng W, Nunes EV. Dronabinol for the treatment of cannabis dependence: a randomized, double-blind, placebo-controlled trial. Drug Alcohol Depend. 2011 Jul 1;116(1-3):142-50.

${ }^{52}$ McRae-Clark AL, Carter RE, Killeen TK, Carpenter MJ, Whalquist AE, Simpson SA, Brady KT. A Placebo-Controlled Trial of Buspirone for the Treatment of Marijuana Dependence. Drug Alcohol Depend. 2009 Nov 1; 105(1-2): 132-138.

${ }^{53}$ Levin FR, Mariani JJ, Pavlicova M, Brooks D, Glass A, Mahony A, et al. Dronabinol and Lofexidine for Cannabis Use Disorder: A Randomized, Double-Blind, Placebo-Controlled Trial. Drug Alcohol Depend._2016 February 1; 159: 53-60.

${ }^{54}$ Marshall K, Gowing L, Ali R, Le Foll B. Pharmacotherapies for cannabis dependence. Cochrane Database Syst Rev. 2014 December 17; 12: CD008940. 